\title{
De los discursos actuales sobre la discapacidad en España $^{1}$
}

\author{
Mario TOBOSO-MARTíN \\ Instituto de Filosofía. Centro de Ciencias Humanas y Sociales, CSIC \\ mario.toboso@cchs.csic.es
}

Recibido: 17-04-2012

Aceptado: 05-10-2012

\begin{abstract}
Resumen
En este artículo tomamos como marco de reflexión la evolución de las políticas sobre discapacidad en España en los últimos 30 años, para desarrollar la idea de que en este tiempo se ha producido lo que vamos a denominar un 'cambio de paradigma' en la interpretación de esta categoría social. Para abordar el análisis de este cambio proponemos una compresión discursiva de la discapacidad, basada en la consideración conjunta de prácticas, representaciones, valores y espacios múltiples en los que llegan a articularse discursos acerca de dicha noción. Estos discursos constituyen los dos paradigmas implicados en el cambio mencionado: el paradigma de la rehabilitación y el paradigma de la autonomía personal. Argumentamos que en España este cambio de paradigma no ha sido completo, sino que se ha dado de manera desigual en diferentes espacios. A partir del planteamiento discursivo que proponemos, realizamos el análisis de dicho cambio de paradigma en el espacio legislativo y señalamos los elementos que han dificultado su realización en otros espacios.
\end{abstract}

Palabras clave discapacidad, discurso, espacios, prácticas, representaciones, valores

\section{On current discourses about disability in Spain}

\begin{abstract}
In this paper we take under consideration the evolution of disability policies in Spain in the last 30 years to develop the idea that in this time has occurred what we call a 'paradigm shift' in the interpretation of this social category. To analyze this shift, we propose a discursive understanding of disability, based on joint consideration of practices, representations, values and multiple spaces in which discourses about disability are constructed. These discourses constitute the two paradigms involved in the mentioned change: the paradigm of rehabilitation and the paradigm of personal autonomy. We argue that in Spain this paradigm shift has not been complete, but has been unevenly in different spaces.
\end{abstract}

${ }^{1}$ Este artículo es un resultado de investigación del proyecto “Quali-TYDES” (Qualitative Tracking with Young Disabled People in European States), European Collaborative Research Projects in the Social Sciences - European Science Foundation (ref. 09-ECRP032), y del proyecto "Innovación oculta: cambio de paradigma en los estudios de innovación”, Ministerio de Economía y Competitividad, Gobierno de España (ref. FFI2011-25475). 
From the proposed discursive approach we reviewed the paradigm shift in the legislative space, and we note the items that have hampered its implementation in other areas.

Key words: disability, discourse, environments, practices, representations, values.

\section{Referencia normalizada}

Toboso Martín, M. (2013). "De los discursos actuales sobre la discapacidad en España”. Política y Sociedad, Vol.50, Núm. 2 681-706

Sumario: 1.Introducción. 2.La plasmación legislativa de los paradigmas sobre discapacidad en España. 3.Propuesta para una comprensión discursiva de la discapacidad. 4.Dimensiones del proceso de cambio del discurso de la rehabilitación al discurso de la autonomía personal. 5.A modo de conclusión.

\section{Introducción}

En las tres últimas décadas las respuestas políticas y legislativas ofrecidas a las cuestiones planteadas en el ámbito de la discapacidad en España han variado de manera sustancial. En el desarrollo de tales respuestas influyen notablemente las concepciones y percepciones sociales acerca de la discapacidad y de las personas con discapacidad (Jiménez y Huete, 2010). Por ello, el análisis de las políticas sobre discapacidad requiere tener en cuenta la evolución en la manera de entender esta realidad humana y social que a lo largo del tiempo se ha conceptualizado de formas muy diferentes (Aguado, 1995; Stiker, 1999).

En este artículo vamos a centrar nuestra atención en los dos 'paradigmas' explicativos básicos que en tiempo más reciente han servido de marcos para la consideración de la discapacidad y de las personas con discapacidad: el llamado 'paradigma de la rehabilitación', cuyo máximo exponente es el denominado 'modelo médico', y el 'paradigma de la autonomía personal', representado principalmente por el denominado 'modelo social' (Hunt, 1966; Finkelstein, 1980; Topliss, 1982; Brisenden, 1986; Abberley, 1987; Oliver, 1990; Barnes, 1991; Morris, 1991; Shakespeare, 1993; Barton, 1996; Oliver, 1996; Swain et al., 2004; Palacios, 2008; Cabrera, 2009). ${ }^{2}$

2 Consideramos, al igual que Díaz (2009), que la noción de 'paradigma', tomada de Kuhn (1979 [1962]), resulta interesante y útil a la hora de analizar el proceso de cambio entre las dos maneras diferentes de interpretar la discapacidad, de las que nos vamos a ocupar a lo largo del artículo. Igualmente, nos parece relevante la interpretación del trabajo de Kuhn realizada por King (1971), que asimila los paradigmas a las prácticas y discursos de las comunidades científicas que articulan su actividad en torno a ellos. 
Desde el punto de vista del paradigma de la rehabilitación se considera la discapacidad como una condición individual, resultado de una deficiencia de la persona a nivel físico, psíquico o sensorial. Se interpreta la discapacidad como una situación de 'enfermedad' y se da por supuesto que las personas con discapacidad deben someterse a un proceso de rehabilitación para asimilarse en la mayor medida posible a las demás personas 'sanas' de la sociedad. Las personas con discapacidad se convierten así en objeto de atención principalmente médica y su realidad es considerada desde una perspectiva notablemente 'medicalizada' y 'medicalizante' (Arnau y Toboso, 2008).

El paradigma de la autonomía personal parte del rechazo de las características del paradigma de la rehabilitación. Considera que la discapacidad no tiene que ver con causas de naturaleza individual y médica, sino sociales, cuyo origen son las limitaciones de la sociedad para ofrecer servicios que tengan en cuenta los requerimientos de funcionamiento (físico, psíquico y sensorial) de todas las personas. Asume que las personas con discapacidad pueden participar en la sociedad en igualdad de condiciones con el resto, lo que exige la inclusión y la aceptación plena de su diferencia. La discapacidad es interpretada como el resultado de una sociedad 'discapacitante' y el modo de atenuarla requiere, por lo tanto, transformar el entorno social.

A nivel internacional, y también en España, se viene produciendo en las últimas tres décadas un paulatino 'cambio de paradigma', desde el paradigma de la rehabilitación hacia el paradigma de la autonomía personal. El proceso de transición entre ambos paradigmas se ha visto jalonado por algunos hitos fundamentales, como el Programa de Acción Mundial para las Personas con Discapacidad (ONU, 1982), con la Declaración del Decenio Mundial de las Personas con Discapacidad (19831992), y la promulgación de las Normas Uniformes sobre la Igualdad de Oportunidades para las Personas con Discapacidad (ONU, 1993) que, si bien no alcanzaron los objetivos planteados de igualdad y plena participación de las personas con discapacidad, orientaron las acciones para la siguiente década, en la que destaca la aprobación por la ONU, en 2006, de la Convención sobre los Derechos de las Personas con Discapacidad (Palacios y Bariffi, 2007; Palacios, 2008; Parra-Dussan, 2010). La transición entre ambos paradigmas puede también identificarse en el largo proceso de revisión conceptual e instrumental que condujo de la Clasificación Internacional de Deficiencias, Discapacidades y Minusvalías (CIDDM, OMS), de 1980, a la Clasificación Internacional del Funcionamiento, la Discapacidad y la Salud (CIF, OMS), de 2001 (Egea y Sarabia, 2001; Díaz, 2009; Rodríguez y Ferreira, 2010).

El cambio de paradigma que nos ocupa puede resumirse en los siguientes aspectos. $\mathrm{Si}$, de acuerdo con el paradigma de la rehabilitación, la discapacidad se ha concebido como una característica individual de la persona y como una desviación negativa (física, psíquica o sensorial) con respecto a un supuesto patrón de normalidad funcional, el paradigma de la autonomía personal interpreta de manera novedosa la discapacidad como el resultado de la interacción entre el entorno social y las personas que difieren de ese supuesto patrón de normalidad, en función del cual se 
configura el acceso a productos y bienes sociales tales como el espacio físico y construido, la comunicación, el trabajo, la educación, la cultura, el ocio, las relaciones personales, etc. (European Commission, 2001; Swain et al., 2004).

El paradigma de la autonomía personal se basa en la constatación de que dicha configuración no es neutra, sino que está sesgada a favor de las características de funcionamiento de quienes constituyen el patrón dominante. Así, por ejemplo, al situar una oficina gubernamental en un tercer piso sin ascensor se está asumiendo que todo usuario posible de la misma está en condiciones de subir las escaleras. Al determinar como método único de votación la elección individual entre papeletas impresas, se asume que todo votante está en condiciones de leer tales papeletas (Courtis, 2004). Los ejemplos en los que el acceso a bienes, productos y servicios de uso general sitúa a las personas ante verdaderos 'lechos de Procusto' podrían multiplicarse (Toboso y Guzmán, 2010).

\section{La plasmación legislativa de los paradigmas sobre discapacidad en España}

La evolución de las políticas sobre discapacidad en España en las tres últimas décadas ha estado ligada a la construcción del sistema público de servicios sociales, que se inició durante la década de los 80 del siglo pasado, a partir de la democratización de las instituciones. Tras la promulgación de la Constitución Española en 1978, se inicia un giro en las políticas de discapacidad, desde un planteamiento centrado exclusivamente en la rehabilitación, del que la Ley de Bases de la Seguridad Social (1963) es quizá el exponente más representativo, hacia uno basado en la equiparación de posibilidades, y posteriormente hacia el enfoque de los derechos y la no discriminación (Jiménez y Huete, 2010).

La Ley 13/1982, de 7 de abril, de Integración Social de los Minusválidos (conocida de manera abreviada como LISMI) supuso la primera concreción del amparo especial que el artículo 49 de la Constitución reconoce a las personas con discapacidad: "Los poderes públicos realizarán una política de previsión, tratamiento, rehabilitación e integración de los disminuidos físicos, sensoriales y psíquicos, a los que prestarán la atención especializada que requieran y los ampararán especialmente para el disfrute de los derechos que este Título (Título I: De los derechos y deberes fundamentales) otorgados a todos los ciudadanos.” La LISMI se basa en el desarrollo de 'acciones' especiales dirigidas a atender a las personas con discapacidad de manera individual, más que a establecer las 'condiciones' generales para eliminar los obstáculos que dificultan su participación en la sociedad y el disfrute de sus derechos. Es un instrumento legal destinado a garantizar derechos de protección, sobre todo en materia de prestaciones económicas y de servicios asistenciales, enmarcable por ello dentro de lo que hemos denominado el paradigma de la rehabilitación.

A pesar de que el artículo 14 de la Constitución afirma que: "Los españoles son iguales ante la Ley, sin que pueda prevalecer discriminación alguna por razón de nacimiento, raza, sexo, religión, opinión o cualquier otra condición o circunstancia 
personal o social”, hasta la aprobación en 2003 de la Ley 51/2003, de 2 de diciembre, de Igualdad de Oportunidades, No Discriminación y Accesibilidad Universal de las personas con discapacidad (conocida como LIONDAU) este artículo no tendría repercusión en el ámbito de la discapacidad, ya que la LISMI, como queda dicho, no se fundamenta en él.

La LIONDAU se basa en los artículos 9.2, 10 y 14 de la Constitución, que garantizan la libertad, la igualdad y la participación social (art. 9.2), la dignidad de la persona (art. 10) y la igualdad ante la ley y la no discriminación (art. 14). Supone, por ello, un avance significativo en la legislación española en materia de discapacidad, que representa la superación casi plena del paradigma de la rehabilitación, reemplazado, al menos sobre el papel, por una perspectiva social en la que se plasman los principios del paradigma de la autonomía personal (Díaz, 2009). Frente a la LISMI, caracterizada por un marcado carácter asistencialista, la LIONDAU no se centra exclusivamente en la atención a las situaciones individuales de las personas con discapacidad (práctica característica del paradigma de la rehabilitación), sino que promueve la necesidad de actuar directamente sobre las dificultades y obstáculos del entorno social (de acuerdo con el paradigma de la autonomía personal). ${ }^{3}$

\section{Propuesta para una comprensión discursiva de la discapacidad}

Según el paradigma de la rehabilitación, la discapacidad remite a aspectos individuales y el supuesto problema se sitúa exclusivamente en las deficiencias y dificultades de quien las padece. Las respuestas políticas y legislativas se basan principalmente en la rehabilitación y atención a esas dificultades. Las personas con discapacidad son el objeto pasivo de actuaciones biomédicas, rehabilitadoras y asistenciales que se realizan a menudo sin tener en cuenta sus propias opiniones y deseos (Martínez-Pérez, 2009). Por otro lado, de acuerdo con el paradigma de la autonomía personal, la discapacidad implica aspectos relacionales, y el problema se

\footnotetext{
${ }^{3}$ Junto a la LISMI y la LIONDAU, otro texto legislativo relevante en materia de discapacidad en España es la Ley 39/2006, de 14 de diciembre, de Promoción de la Autonomía Personal y Atención a las personas en situación de dependencia (conocida como Ley de dependencia). Aprobada pocos días después de la Convención sobre los Derechos de las Personas con Discapacidad (ONU, 2006), la Ley 39/2006 trata de afrontar el 'problema social' derivado de la creciente tasa de dependencia motivada por el envejecimiento de la población. En su redacción se plantea un equilibrio muy problemático entre la 'promoción de la autonomía personal' y la 'atención a las personas en situación de dependencia' que, finalmente, se decanta de manera mayoritaria en su articulado hacia esta segunda posición. Por una mayor claridad de nuestra exposición, no trataremos aquí sobre la consideración de esta ley entre los dos paradigmas que nos ocupan, cuestión que ya ha sido estudiada en otros trabajos (Díaz, 2010; Guzmán, Moscoso y Toboso, 2010; Guzmán, Toboso y Romañach, 2010).
} 
sitúa en la sociedad, en vez de en la persona. Las respuestas políticas y legislativas persiguen la eliminación de las barreras que discriminan y limitan su participación e igualdad de oportunidades. Las personas con discapacidad son consideradas en este caso como sujetos activos de derechos civiles (Jiménez y Huete, 2010).

Nuestra propuesta para una comprensión de la discapacidad, que denominamos 'discursiva', se basa en la observación de que ambos paradigmas incorporan diferentes conjuntos de 'prácticas' relacionadas, igualmente, con 'representaciones' muy distintas de la discapacidad y de las personas con discapacidad. ${ }^{4}$ Tales prácticas y representaciones se localizan en múltiples 'espacios' (o entornos): el espacio social, el político, el legislativo, el biomédico, el actitudinal, el entorno educativo, el laboral, etc. En todos estos espacios se inscriben los conjuntos de prácticas y representaciones de la discapacidad y de las personas con discapacidad, e igualmente se verifica en ellos la relación entre tales conjuntos.

El conjunto de prácticas relativas al paradigma de la rehabilitación incluye, entre otras, el tratamiento paternalista y la intervención asistencial desde un supuesto ‘conocimiento experto' sobre la situación y necesidades de las personas con discapacidad. La discapacidad se representa como enfermedad y manifestación patológica incapacitante y limitadora de la autonomía. Tales prácticas, llevadas a cabo principalmente en el espacio biomédico, se trasladan al espacio social como prácticas de institucionalización de la persona en espacios asistenciales, como resultado de su asimilación a dichas representaciones 'minusvalidantes', e incluso llegan al espacio político-legislativo, en el que finalmente adquieren el carácter de prácticas y representaciones recogidas y sancionadas en textos legislativos (Martínez-Pérez, 2009).

El conjunto de prácticas atribuibles al paradigma de la autonomía personal surge como respuesta a las anteriores, con una componente fundamentalmente emancipadora desde la que se reivindica un imaginario totalmente opuesto a las representaciones del paradigma de la rehabilitación. Surge la consideración de la persona con discapacidad como 'sujeto' de derechos, lejos de su visión como mero 'objeto' de asistencia rehabilitadora; unos derechos que se reivindican desde la afirmación de su autonomía y capacidad de decisión, desde la exigencia de respeto a las mismas y a la igualdad de oportunidades en todos los espacios y entornos de la sociedad. Por ello, la desmedicalización y la desinstitucionalización de las personas con discapacidad son prácticas irrenunciables en el paradigma de la autonomía personal (García-Alonso, 2003).

Las prácticas de cada paradigma se relacionan dentro del mismo con las representaciones correspondientes de la discapacidad y de las personas con discapacidad.

\footnotetext{
${ }^{4}$ Sobre la noción de ‘discurso’ que vamos a manejar a lo largo del artículo, que implica la consideración conjunta de elementos prácticos, representacionales y axiológicos, por parte de comunidades concretas en espacios concretos, véase, por ejemplo, Woolgar (1986), Lynch (1988), Lynch y Woolgar (1988), Jordan y Lynch (1998) y Livingston (1999).
} 
Esta relación entre los conjuntos de prácticas y representaciones se lleva a cabo en cada espacio y entorno concreto, y contribuye a la estabilidad de ambos conjuntos; es decir, las prácticas y representaciones correspondientes se estabilizan mutuamente, y la estabilidad de estos elementos discursivos conduce, de hecho, a la propia definición, estabilidad y permanencia de los espacios y entornos que los acogen (Toboso y Guzmán, 2009).

Nuestra propuesta supone, además, que la relación entre los conjuntos de prácticas y representaciones en un espacio dado viene mediada por los 'valores' inscritos en ese espacio, que son característicos y definitorios del mismo. ${ }^{5}$ Consideremos como ejemplo de tal espacio un hospital, o una clínica de rehabilitación. Notamos de manera inmediata que se trata de espacios plagados de valores propios característicos que, en la forma de diferentes códigos, protocolos y normas implícitas y explícitas de funcionamiento que deben satisfacerse, articulan prácticas y representaciones en continua circulación interna, las cuales definen precisamente las características de tales entornos como espacios discursivos (Berg, 1998; Mol, 2002). Adicionalmente, el acuerdo sobre aquellos valores contribuye a la identidad de la 'comunidad' (médicos, terapeutas, rehabilitadores, etc.) que en cada espacio particular ostenta el poder de articular los discursos de autoridad acerca del 'objeto' en cuestión. ${ }^{6}$

Así, si en un espacio dado se considera, por ejemplo, que la autonomía (física o moral) de las personas es un valor a satisfacer, la atribución de valor a la representación 'persona autónoma' pondrá en marcha en ese espacio una serie de prácticas relacionadas. Por lo tanto, al considerar que una persona no está dotada de autonomía suficiente, se proyectará sobre ella una representación 'de-valuada' y un con-

${ }^{5}$ La dimensión axiológica de este trabajo remite a las investigaciones de Javier Echeverría sobre axiología de la ciencia y la tecnología, expuestas en numerosas publicaciones (sirvan como orientación: 1995, 2002a, 2002b, 2003). El aspecto fundamental que nos interesa en el desarrollo de este artículo es la interpretación de los valores, no como propiedades del objeto, ni como la proyección estimativa del sujeto sobre aquel, sino como el resultado mismo de la acción de evaluar, es decir, de aplicar funciones axiológicas a variables axiológicas adecuadas (Echeverría, 2002b).

${ }^{6}$ El 'objeto' discursivo que, a tal respecto, nos interesa en este artículo es la 'discapacidad'. No obstante, otros objetos de notable interés son la raza, el género, la orientación sexual, la edad, el cuerpo, la capacidad, el funcionamiento, la tecnología, la ciencia, la salud, la vida, la muerte, etc., y en general, cualquier objeto de discurso cuya reflexión se plantee en múltiples espacios interrelacionados, que albergarán acerca de ese objeto conjuntos diferentes de prácticas, representaciones y valores. Ligada estrechamente a cada espacio particular en el que se consideren esos conjuntos, estará la comunidad (de “miembros”, en la perspectiva etnometodológica; Garfinkel, 2006 [1967]) que sostiene en ellos su discurso propio acerca del objeto en cuestión resultante de la interrelación de los mencionados conjuntos de prácticas, representaciones y valores. 
junto de prácticas materiales, simbólicas, discursivas, actitudinales, etc., conforme a esa representación. ${ }^{7}$

Cuando en un espacio determinado 'algo' es considerado como un valor a satisfacer (pongamos por ejemplo, 'la autonomía' o 'la salud' en el espacio biomédico), habrá que tener en cuenta no sólo las prácticas y representaciones que se desarrollan a partir de esa consideración de valor, sino también las prácticas y representaciones previas de las que resulta eso mismo como cualidad valorada. Es decir, habrá que considerar tanto la dinámica 'ex post' de prácticas y representaciones que el valor produce, como la dinámica 'ex ante' que da lugar a la atribución de valor. Ambas dinámicas están relacionadas, y se estabilizan precisamente en torno a la cualidad valorada en cuestión. Así, por ejemplo, cuando en el espacio biomédico se considera la salud como una cualidad tal a satisfacer, las prácticas y representaciones que produce esta atribución de valor se orientan hacia la satisfacción del mismo, es decir, hacia la consecución de la salud mediante, pongamos por caso, prácticas biomédicas, tratamientos adecuados, la definición e imposición de estilos de vida saludables, etc. Por otro lado, que la salud llegue a ser considerada como una cualidad valorada a satisfacer remite, al margen de otros intereses, ${ }^{8}$ a la negativización de su contravalor, 'la enfermedad'; es decir, a su representación negativizada y devaluada, y a las prácticas conformes a esta representación: la necesidad de intervenir sobre ella y erradicarla.

De manera que, en parte, de la representación negativizada de la enfermedad y de la consecuente necesidad de eliminarla, emerge 'ex ante' la salud como una cualidad valorada, y su instalación en la esfera de los valores del espacio biomédico produce 'ex post' la definición de un conjunto de prácticas tendentes, precisamente, a satisfacer ese valor y oponerse a su contravalor, por medio de las prácticas y representaciones congruentes en cada caso.

Las prácticas y representaciones dentro de un entorno dado se orientan hacia la satisfacción del conjunto de valores inscrito en el mismo. La satisfacción de los valores característicos de un entorno se relaciona por igual con la conformidad de

${ }^{7}$ En este punto, claramente, debemos preguntarnos cómo se llega a la consideración de que esa persona en particular carece de autonomía, o no satisface ese valor en grado suficiente. Parece evidente que, de alguna manera, se pone en juego desde el inicio una representación social previa, en forma de estereotipo o "fórmula-receta" (García de la Cruz, 2008), y la valoración final arrojada se basa en la diferencia entre esta representación abstracta y la concreción ofrecida por la persona. Se ve aquí la relevancia no sólo de esa representación previa que determina la atribución de valor (qué se entiende por 'autonomía' y 'persona autónoma', en este caso), sino también la influencia del espacio en el que se genere y dęl que proceda esa representación previa.

8 Intereses particulares, obviamente, de los numerosos actores que conforman la 'industria’ mundial de la salud: corporaciones biomédicas, farmacéuticas y alimentarias, entidades supranacionales que diseñan los estilos de vida saludable (OMS, FAO, FDA, etc.), gobiernos, medios de comunicación, etc. (Lupton, 1995). 
las prácticas que hacia aquella satisfacción se orientan y con la congruencia de las representaciones implicadas. Vamos a denominar 'racionalidad' del discurso a la reunión de estas tres condiciones: satisfacción, conformidad y congruencia, como tres caracteres inseparables de la misma cualidad: la racionalidad del discurso acerca del objeto en cuestión en el espacio dado. La racionalidad del discurso puede articularse en torno a los valores (racionalidad axiológica), a las representaciones (racionalidad representacional) o a las prácticas (racionalidad práctica) presentes en el entorno dado, si bien teniendo en cuenta la imbricación discursiva entre valores, representaciones y prácticas, todo discurso incluirá, en mayor o menor medida, estas tres clases de racionalidad.

Asumimos, además, que en tanto no se consideren otros entornos posibles distintos de aquel en el que se considera inicialmente el discurso, los tres caracteres recién mencionados se determinan mutuamente, resultando para el discurso una racionalidad, o lógica, que podríamos considerar casi 'tautológica'. Por lo tanto, la sustitución de un discurso dado por otro discurso diferente, definidos ambos en el mismo espacio (por ejemplo, la sustitución de una ley dada por una nueva ley acerca del mismo objeto, en el espacio legislativo), va a requerir la participación de otros espacios discursivos, desde los que promover la migración de nuevos valores al espacio en el que se desean modificar los antiguos valores insertos en el discurso inicial. La posibilidad de modificar y desplazar estos viejos valores requiere la adopción de nuevas prácticas y representaciones provenientes de otro(s) espacio(s), orientadas hacia la satisfacción de los nuevos valores. Es así como, por la influencia de valores nuevos provenientes de otro(s) espacio(s), el discurso acerca de un objeto en un cierto espacio puede devenir otro discurso diferente. La apertura discursiva de los distintos espacios y la consiguiente posibilidad de influencia mutua entre unos y otros, es la responsable de que los discursos definidos en ellos puedan efectivamente cambiar.

Volviendo al ámbito de nuestro 'objeto', la discapacidad, vamos a interpretar los paradigmas de la rehabilitación y de la autonomía personal como sendos discursos acerca de la misma, constituidos a partir de la interrelación de diferentes conjuntos de prácticas, representaciones y valores, situados en múltiples espacios. Diremos, entonces, que la racionalidad del paradigma de la rehabilitación se articula, entre otras, en torno a prácticas como la medicalización, el paternalismo, el supuesto conocimiento experto, la institucionalización y la rehabilitación de la persona, conformes a representaciones como enfermedad, dependencia, paciente, 'objeto' de atención médica y deficiencia (entendida como una atribución orgánica). Por otra parte, la racionalidad que articula el discurso del paradigma de la autonomía personal incluirá entre sus prácticas la desmedicalización, la vida independiente, la emancipación, la desinstitucionalización y la rehabilitación de la sociedad, conformes a representaciones como funcionamiento, autonomía, persona, 'sujeto' de derechos civiles y discapacidad (entendida como una construcción social).

Como ya hemos mencionado, en las últimas tres décadas el paradigma (o discurso, diremos en adelante) de la autonomía personal viene imponiendo muy lentamente su propia racionalidad, al menos en algunos espacios relevantes (como el espacio 
legislativo), pero no en todos, como veremos al analizar la evolución de estos discursos en España. Por ello, en lo tocante a la consideración social actual de la discapacidad, puede decirse que ambos discursos conviven en los numerosos espacios interrelacionados en los que se sitúan.

\section{Dimensiones del proceso de cambio del discurso de la rehabilitación al dis- curso de la autonomía personal}

\subsection{De la equiparación de posibilidades a la igualdad de oportunidades}

En la LISMI (1982) ocupa un lugar central el principio que podemos denominar de ‘equiparación de posibilidades' (BOE, 2003), basado en la provisión de apoyos complementarios específicos orientados a reducir las desventajas individuales de las personas con discapacidad. La LISMI consideró que tales prácticas de atención y medidas de equiparación individual consistían básicamente en esos apoyos, ayudas técnicas y servicios asistenciales especializados dirigidos a la persona.

De manera muy diferente, en la Exposición de Motivos de la LIONDAU (2003) se destacan, entre las razones que llevaron al desarrollo de esta ley, los cambios en la concepción social de la discapacidad, en consonancia con un nuevo enfoque orientado hacia la eliminación de las barreras del entorno y no únicamente hacia la atención a las situaciones individuales:

"Dos razones justifican esta nueva ley: la persistencia en la sociedad de desigualdades, pese a las inequívocas proclamaciones constitucionales y al meritorio esfuerzo hecho a partir de aquella ley [la LISMI], y, lo que es más importante todavía, los cambios operados en la manera de entender el fenómeno de la «discapacidad» y, consecuentemente, la aparición de nuevos enfoques y estrategias: hoy es sabido que las desventajas que presenta una persona con discapacidad tienen su origen en sus dificultades personales, pero también y sobre todo en los obstáculos y condiciones limitativas que en la propia sociedad, concebida con arreglo al patrón de la persona media, se oponen a la plena participación de estos ciudadanos." (BOE, 2003)

La LIONDAU plantea un renovado impulso de las políticas de discapacidad mediante la incorporación de nuevas garantías y conjuntos de prácticas para hacer efectivo el derecho a la 'igualdad de oportunidades', como valor central de la misma. Para ello se considera que:

“[...] es preciso diseñar y poner en marcha estrategias de intervención que operen simultáneamente sobre las condiciones personales y sobre las condiciones ambientales. En esta perspectiva se mueven dos estrategias de intervención relativamente nuevas y que desde orígenes distintos van, sin embargo, convergiendo progresivamente. Se trata de la estrategia de «lucha contra la discriminación» y la de «accesibilidad universal».” (BOE, 2003) 
La falta de accesibilidad de los entornos, productos y servicios, como "una forma sutil pero muy eficaz de discriminación”, genera desventajas a las personas con discapacidad en relación con aquellas que no lo son:

"Convergen así las corrientes de accesibilidad y de no discriminación. Pues bien, en esta ley se recogen estas dos nuevas corrientes y confluyen con la ya antigua pero vigente LISMI, que desarrolló sobre todo medidas de acción positiva.”9 (BOE, 2003)

Así pues, no discriminación, accesibilidad universal y acciones positivas constituyen la terna de estrategias en cuyas prácticas se basa el planteamiento de la LIONDAU para tratar de garantizar el derecho de las personas con discapacidad a la igualdad de oportunidades en todos los entornos de la sociedad.

\subsection{De las medidas asistenciales a la lucha contra la discriminación de las personas con discapacidad}

En el Título I, Principios Generales, de la LISMI, en su artículo 1 se hace mención a los principios que la inspiran, que, fundamentados en los derechos reconocidos en el artículo 49 de la Constitución, se orientan a satisfacer la completa realización personal y la total integración social de las personas con discapacidad (a excepción de aquellos "disminuidos profundos" que precisen asistencia o tutela). En el artículo 3 se exponen los principales medios que los poderes públicos utilizarán para ello, constituyendo una obligación del Estado: "la prevención, los cuidados médicos y psicológicos, la rehabilitación adecuada, la educación, la orientación, la integración laboral, la garantía de unos derechos económicos, jurídicos sociales mínimos y la Seguridad Social” (BOE, 1982).

En el artículo 3 de la LISMI se señalan, por tanto, los entornos básicos de intervención de la ley, recién enumerados. En ellos cada comunidad autolegitimada de supuestos expertos (médicos, psicólogos, rehabilitadores, educadores, orientadores, etc.) que comparten su acuerdo en torno a la representación valorativa (evaluación) de las personas con discapacidad (“minusválidos” en los términos de la ley), pondrán en marcha los conjuntos de prácticas y representaciones ya mencionados como característicos del discurso de la rehabilitación y de su racionalidad propia. Se trata de las prioridades médicas y asistenciales, que tienen como objetivo la adaptación

\footnotetext{
${ }^{9}$ Entre tales medidas, la LISMI desarrolló un sistema de prestaciones sociales y económicas para las personas con discapacidad que por carecer de una actividad laboral no estuviesen incluidas en el sistema de la Seguridad Social, que se consolidó varios años más tarde con la Ley de Prestaciones no Contributivas de 1990. En el entorno laboral impulsó las políticas de integración mediante la creación de los Centros Especiales de Empleo y la reserva del $2 \%$ de los puestos de trabajo en las empresas de más de 50 trabajadores, dando rango legal al precedente que había sentado el Real Decreto 2531/70, de 22 de mayo de 1982, sobre empleo de trabajadores minusválidos (Jiménez y Huete, 2010).
} 
individual y la integración de la persona al medio social, en lugar de la priorización de otros objetivos y prácticas derivadas de políticas de inclusión, centradas en la eliminación de los obstáculos sociales y en la lucha contra la discriminación.

En el artículo 1 de la LIONDAU se señala como objetivos de la ley: "establecer medidas para garantizar y hacer efectivo el derecho a la igualdad de oportunidades de las personas con discapacidad”, entendiendo dicha igualdad de oportunidades como "la ausencia de discriminación, directa o indirecta, que tenga su causa en una discapacidad, así como la adopción de medidas de acción positiva orientadas a evitar o compensar las desventajas de una persona con discapacidad para participar plenamente en la vida política, económica, cultural y social” (BOE, 2003).

En el artículo 2 se destacan los Principios que inspiran la ley: vida independiente, normalización, accesibilidad universal, diseño para todos, diálogo civil y transversalidad de las políticas en materia de discapacidad (BOE, 2003). El principio de "vida independiente" supone allanar el camino para permitir a la persona con discapacidad gobernar su propia vida y participar en la comunidad. En la misma línea, el "diálogo civil" se refiere a la participación necesaria de las organizaciones de personas con discapacidad en la elaboración, ejecución, seguimiento y evaluación de las políticas que les afecten. El principio de "normalización" se refiere a la necesidad de que las personas con discapacidad compartan los mismos lugares, ámbitos, bienes y servicios que cualquier otra persona. En sentido similar, el principio de "transversalidad de las políticas en materia de discapacidad" supone la integración de la perspectiva de la discapacidad en toda política pública. Los principios de "diseño para todos" y de "accesibilidad universal” están conectados con la condición que deben cumplir, en general, los entornos, procesos, bienes, productos y servicios, así como los objetos, instrumentos, herramientas y dispositivos para poder ser utilizados por todas las personas (Courtis, 2004).

Los Principios recién enumerados pueden considerarse como descriptivos del conjunto de valores que inspiran la LIONDAU, como expresión del discurso de la autonomía personal en el espacio legislativo. Se trata, como vemos, de valores sobre los cuales muy difícilmente podrían articularse los conjuntos de prácticas y representaciones característicos del discurso de la rehabilitación expresado en la LISMI.

\subsection{Del enfoque individual a la perspectiva social de la discapacidad}

El enfoque estructural de la LIONDAU, de actuación hacia las condiciones del entorno social, se complementa con las acciones positivas y las medidas redistributivas del enfoque hacia el individuo característico de la LISMI, dirigidas a compensar las desventajas creadas por el entorno y a equiparar las posibilidades de la persona con discapacidad (artículos 8 y 9 de la LIONDAU). Entre estas medidas individuales se consideran: criterios y prácticas más favorables hacia las personas con discapacidad, el acceso a ayudas técnicas y económicas, asistencia personal, servicios especializados y ayudas y servicios auxiliares para la comunicación. 
Por lo tanto, si bien es cierto que la LIONDAU incorpora en su planteamiento la orientación 'individual' de la LISMI, la enmarca, no obstante, en una perspectiva estructural 'social' que aboga por la eliminación de todas las barreras que 'discapacitan' a las personas, en la que se combinan las estrategias de no discriminación y accesibilidad universal con el objetivo de garantizar su igualdad de oportunidades. Únicamente dentro del marco de este planteamiento social (propio de la LIONDAU), las acciones específicas que en el planteamiento individual (de la LISMI) se dirigían a la equiparación de las posibilidades de cada persona, llegan a contribuir a satisfacer el objetivo de la igualdad de oportunidades de las personas con discapacidad. Podríamos decir, al respecto, que la LIONDAU ofrece el marco adecuado de condiciones sociales que permite situar en una perspectiva plenamente social las acciones individuales contenidas en la LISMI.

En ausencia de un marco tal de condiciones sociales (como el ofrecido por la LIONDAU), las políticas que (como la LISMI) desarrollan únicamente acciones individuales específicas hacia las personas con discapacidad, contribuyen a reforzar los estereotipos negativos y la percepción devaluada sobre ellas, como personas siempre menesterosas, dependientes e incapaces de valerse por sí mismas (Courtis, 2004). La mayoría de las políticas tradicionales destinadas a la discapacidad se han basado en una concepción 'individual' de la misma de naturaleza médica o, aún peor, caritativa, y han representado reiteradamente a las personas con discapacidad como débiles, merecedoras de caridad y destinatarias de ayudas compensatorias por su evidente 'tragedia personal' (Oliver, 1990; Shapiro, 1994).

El artículo 7.1 de la LISMI define qué es lo que se entenderá por persona con discapacidad (“minusválida”, en la terminología de la ley), lo cual resulta muy esclarecedor a la hora de comprender la representación social de la discapacidad que incorpora esta ley:

“[...] se entenderá por minusválido toda persona cuyas posibilidades de integración educativa, laboral o social se hallen disminuidas como consecuencia de una deficiencia, previsiblemente permanente, de carácter congénito o no, en sus capacidades físicas, psíquicas o sensoriales”.

Se define la 'minusvalía' desde una perspectiva exclusivamente individual, considerando que la disminución de las posibilidades de integración educativa, laboral o social son consecuencia únicamente de las deficiencias en las capacidades físicas, psíquicas o sensoriales de la persona. No se hace mención alguna a los obstáculos y barreras de todo tipo existentes en el entorno como posible causa de las dificultades en su integración social. De acuerdo con esta representación de la discapacidad, centrada exclusivamente en la persona, se entiende que el discurso contenido en la LISMI dirija su conjunto de prácticas, como no podía ser de otra manera, a garantizar derechos asistenciales (atención médico-rehabilitadora y prestaciones económicas) con el fin de proteger a un colectivo siempre menesteroso, que por sus propias características ve reducidas sus posibilidades de integración social, educativa y laboral (Díaz, 2008). 
Por su parte, en lo tocante a la representación de la discapacidad, el artículo 1.2 de la LIONDAU establece que: “A los efectos de esta ley, tendrán la consideración de personas con discapacidad aquellas a quienes se les haya reconocido un grado de minusvalía igual o superior al 33 por ciento. En todo caso, se considerarán afectados por una minusvalía en grado igual o superior al 33 por ciento los pensionistas de la Seguridad Social que tengan reconocida una pensión de incapacidad permanente en el grado de total, absoluta o gran invalidez, y a los pensionistas de clases pasivas que tengan reconocida una pensión de jubilación o de retiro por incapacidad permanente para el servicio o inutilidad. La acreditación del grado de minusvalía se realizará en los términos establecidos reglamentariamente y tendrá validez en todo el territorio nacional.” (BOE, 2003)

Esta definición remite a una concepción individual de la discapacidad más propia del discurso de la rehabilitación que del discurso de la autonomía personal, en el que se sitúa la LIONDAU (Courtis, 2004). Definiciones de este tipo podrían ser aceptables, pues, en normas que tengan como fin distribuir beneficios a nivel individual (que era el objetivo asistencial de la LISMI), pero la LIONDAU no está destinada a ello, sino, entre otros objetivos, a luchar contra la discriminación. Para este fin debería ser irrelevante el "porcentaje de discapacidad" que se alegue, ya que los prejuicios y barreras sociales que producen la discriminación afectan a cualquier persona sobre la que se proyecte una representación social devaluada, con independencia de la causa concreta que la motive. La discriminación resultante de esa percepción devaluada debería ser objeto de prevención y sanción por parte de la ley, aunque no se registren limitaciones en su actividad que requieran ayudas técnicas o adaptaciones materiales del entorno. La definición dada en la LIONDAU pone a estas personas en la peor situación posible, ya que son víctimas de discriminación social y de violencia simbólica y actitudinal, pero no reúnen el "porcentaje de discapacidad" necesario para recibir la tutela de la ley. ${ }^{10}$

Es notable en este punto la incoherencia discursiva que alberga la LIONDAU, entre la definición (representación) de las personas con discapacidad, enunciada en su redacción original, anclada en un planteamiento normativo y asistencialista de la

${ }^{10} \mathrm{El}$ texto citado en el párrafo precedente es el que aparece en la redacción original de la LIONDAU (2003). En virtud de la Ley 26/2011, de 1 de agosto, de adaptación normativa a la Convención Internacional sobre los Derechos de las Personas con Discapacidad, se añadió, precediendo al texto citado, lo siguiente: "Son personas con discapacidad aquellas que presenten deficiencias físicas, mentales, intelectuales o sensoriales a largo plazo que, al interactuar con diversas barreras, puedan impedir su participación plena y efectiva en la sociedad, en igualdad de condiciones con los demás.

Las medidas de defensa, de arbitraje y de carácter judicial, contempladas en esta Ley serán de aplicación a las personas con discapacidad, con independencia de la existencia de reconocimiento oficial de la situación de discapacidad o de su transitoriedad. En todo caso, las Administraciones públicas velarán por evitar cualquier forma de discriminación que afecte o pueda afectar a las personas con discapacidad.” 
discapacidad enmarcable dentro del discurso de la rehabilitación, y las prácticas correspondientes al discurso de la autonomía personal en el que se inscribe esta ley. Este anclaje y fijación de la representación en un discurso ya superado sería, en nuestra opinión, responsable de paralizar muchos de los cambios que, sobre todo en el espacio actitudinal, debería haber traído consigo el cambio de discurso, incompleto y truncado en la práctica.

\subsection{De las acciones de integración a las condiciones para la inclusión social de las personas con discapacidad}

Una vez definida su población objeto, en el texto de la LISMI se dedican los siguientes Títulos a especificar sus ámbitos de intervención, enunciados en el siguiente orden: Prevención de las minusvalías (Título III), Diagnóstico y Valoración (Título IV), Sistema de prestaciones sociales y Económicas (Título V), Rehabilitación (Título VI, con sus correspondientes secciones: rehabilitación médicofuncional, tratamiento y orientación psicológica, educación y recuperación profesional), Integración Laboral (Título VII), Servicios Sociales (Título VIII) y Otros aspectos (Título IX, donde se incluyen aspectos como la movilidad y las barreras arquitectónicas, y la delimitación de profesionales de los diferentes servicios).

Esta ordenación de Títulos revela, de nuevo, unas prioridades claras, donde ocupan un lugar destacado las acciones médico-rehabilitadoras y las prestaciones asistenciales sociales y económicas (aunque finalmente sólo se desarrollaron prestaciones económicas), en vez de la intervención sobre las condiciones estructurales del entorno. Es igualmente esclarecedor que la educación y la recuperación profesional (como paso previo para la integración laboral), se incluyan en ámbito de la Rehabilitación. Esto es, se conciben no como un derecho social para posibilitar cambios estructurales en la posición social de las personas con discapacidad, sino como fases necesarias dentro de sus procesos de rehabilitación y adaptación social, pues es propio del discurso de la rehabilitación representar a las personas con discapacidad al margen del sistema general de los espacios sociales habituales e insertos en trayectorias de vida especiales (Díaz, 2008).

El Título VI, De la rehabilitación, es el más amplio, de acuerdo con la concepción paradigmática rehabilitadora de la ley. Se compone de varias secciones, que representan las etapas en el proceso de rehabilitación "dirigido a que los minusválidos adquieran su máximo nivel de desarrollo personal y su integración en la vida social, fundamentalmente a través de la obtención de un empleo adecuado” (art. 18). La integración se concibe como el punto final de un proceso de rehabilitación de la persona para su adaptación al medio social. La secuencia rehabilitadora hacia esta adaptación implica: rehabilitación médico-funcional, tratamiento y orientación 
psicológica, ${ }^{11}$ educación general o especial y recuperación profesional, para la posterior integración laboral (Díaz, 2008).

El Título VII, De la integración laboral es igualmente amplio e importante en la LISMI, aunque la mayoría de los preceptos de inserción laboral allí enunciados quedaron pendientes de una regulación posterior. Para hacer efectiva la integración laboral de las personas con discapacidad, la LISMI contemplaba dos vías (art. 37): el sistema productivo ordinario (que la ley considera prioritario siempre que resulte posible) y, en el caso de los minusválidos que por la naturaleza o las consecuencias de sus minusvalías no puedan ejercer una actividad laboral en las condiciones habituales (art. 41), el empleo protegido, mediante su acceso a los Centros Especiales de Empleo.

Esta 'puerta abierta' dejada a las medidas especiales en condiciones segregadas, como práctica típica del discurso de la rehabilitación ligada a representaciones minusvalidantes de las personas con discapacidad, contribuiría posteriormente a que en la promoción del colectivo primasen, de hecho, tales recursos especiales en perjuicio de su integración en los recursos ya existentes de carácter general. Con ello aludimos a recursos de carácter específico, no sólo en el entorno laboral, sino también, por ejemplo, en el entorno educativo, desarrollados a través de prácticas como el empleo protegido y la educación especial, y por extensión a todos aquellos recursos (tanto bienes, como productos y servicios) que dentro de espacios generales de participación social segregan la presencia y la participación en los mismos de las personas con discapacidad.

Como resultado de la permanencia y fijación de una representación devaluada de las personas con discapacidad, anclada como estereotipo negativo en el imaginario social, se articula, en coherencia con la racionalidad del discurso de la rehabilitación, la práctica de su integración segregada, alejada de las condiciones generales y las prácticas de inclusión necesarias dentro de un marco de igualdad de oportunidades.

De acuerdo con este marco, las políticas destinadas a la inclusión de las personas con discapacidad en todos los espacios de la vida social deberían poner el énfasis en la eliminación de los obstáculos, los estereotipos sociales y las barreras físicas, actitudinales y de cualquier tipo, que impiden a las personas con discapacidad llevar adelante su potencial y autonomía. La fijación y permanencia de representaciones devaluantes de las personas con discapacidad en numerosos espacios de actividad y participación (entorno educativo y laboral, pongamos por caso) trae consigo conjuntos de prácticas ajenas al objetivo de su inclusión social. Priman, por el contrario,

11 "El tratamiento y la orientación psicológica estarán presentes durante las distintas fases del proceso rehabilitador, e irán encaminadas a lograr del minusválido la superación de su situación y el más pleno desarrollo de su personalidad.” (BOE, 1982: art. 22.1). Vemos en este artículo de la LISMI la expresión clara de un elemento básico del discurso de la rehabilitación: la dimensión de ‘tragedia personal’ atribuida a la discapacidad (Oliver, 1990). 
conforme a tales representaciones, prácticas de desplazamiento y segregación en subespacios específicos (educación especial y empleo protegido) que se desarrollan al margen de las actividades, objetivos e intereses principales del espacio en cuestión, en el que a falta de las condiciones de base de un marco de igualdad de oportunidades para todas las personas, esos subespacios permanecerán como 'ghettos de integración', en las antípodas de lo que deberían ser ‘nichos para la inclusión’ de las personas con discapacidad.

Finalmente, el Título IX de la LISMI, referente a Movilidad y barreras arquitectónicas, plantea que tanto la edificación (pública y privada) como la planificación urbanística han de ser accesibles para las personas con discapacidad, adelantando una visión propia del discurso de la autonomía personal. Sin embargo, el escaso desarrollo de este articulado en normativas reguladoras posteriores y su reducido seguimiento (no sujeto su incumplimiento a sanción alguna) en las normativas técnicas de edificación, redujeron estos artículos a papel mojado. La accesibilidad es considerada, no como un valor rector de las acciones contenidas en la LISMI, ni como una condición general necesaria para la igualdad de oportunidades, sino como una acción especial más, dirigida de manera específica y exclusiva a atender las necesidades de movilidad de los minusválidos. La importancia casi nula de la accesibilidad en el discurso de la rehabilitación correlaciona de manera 'lógica' con la importancia casi nula de las necesidades de movilidad mencionadas y, de nuevo, con las representaciones sociales devaluantes y de prescindencia de las necesidades de las personas con discapacidad implicadas en este discurso. Debido a su incumplimiento sistemático en la LISMI y a la nueva visión emergente del discurso de la autonomía personal, la "accesibilidad universal” ocupará un lugar fundamental en la LIONDAU (Díaz, 2008).

El adjetivo "universal” que acompaña a la accesibilidad en el texto de la LIONDAU, que expresa la posibilidad de acceso de todas las personas a todos los entornos (edificación, transporte, comunicación, información, educación, empleo, ocio, etc.), es denotativo del cambio de discurso llevado a cabo, desde prácticas centradas únicamente en la supresión de barreras físicas, hacia una dimensión más preventiva y amplia de las mismas, generalizable a todo tipo de espacios, productos y servicios. En consonancia con esta nueva perspectiva, la accesibilidad, planteada originalmente como necesidad de un único colectivo, ha ido adquiriendo un reconocimiento social como elemento que mejora la calidad de vida de todas las personas. Lo que era una necesidad de 'algunos', se ha convertido en un beneficio para 'todos', de manera que las acciones que se realizan para mejorar la accesibilidad, reivindicadas por las personas con discapacidad, benefician a todo el conjunto de la sociedad (IMSERSO, 2004). ${ }^{12}$

${ }^{12}$ Se calcula que el conjunto de personas beneficiarias de las condiciones de accesibilidad reivindicadas por el colectivo de las personas con discapacidad en España podría llegar al 40\% de la población total (IMSERSO, 2004). Por otro lado, es necesario recordar que en 
Es así como, más allá de las acciones específicas características de la LISMI, se relacionan dos de los Principios que inspiran la LIONDAU, el de 'accesibilidad universal' y el de 'transversalidad de las políticas en materia de discapacidad', como principio en virtud del cual "las actuaciones que desarrollan las Administraciones públicas no se limitan únicamente a planes, programas y acciones específicos, pensados exclusivamente para estas personas, sino que comprenden las políticas y líneas de acción de carácter general en cualquiera de los ámbitos de actuación pública, en donde se tendrán en cuenta las necesidades y demandas de las personas con discapacidad.” (BOE, 2003).

A todos los Principios expuestos en el artículo 2 de la LIONDAU subyace implícitamente la consideración de la plena posibilidad de las personas con discapacidad para desempeñarse en la vida social, siempre que los requerimientos de accesibilidad eliminen las barreras que impiden su participación en igualdad de oportunidades. La ley es amplia en cuanto a sus ámbitos de aplicación que, de acuerdo con el principio de transversalidad recién citado son (art. 3): a) Telecomunicaciones y sociedad de la información, b) Espacios públicos urbanizados, infraestructuras y edificación, c) Transportes, d) Bienes y servicios a disposición del público, y e) Relaciones con las Administraciones públicas. Se considera también, con carácter supletorio a lo dispuesto en la legislación específica, el ámbito del empleo y la ocupación.

La LIONDAU supone, con relación a la LISMI, un avance esencial en la concepción social de las personas con discapacidad en la legislación española, puesto que centra su acción en la eliminación de las barreras y obstáculos del entorno social. Sin embargo, aunque garantiza derechos sociales subjetivos para facilitar el desarrollo de la autonomía de las personas con discapacidad, al no figurar dentro de la propia ley los controles administrativos y el régimen sancionador necesario para velar por su cumplimiento, se ha reducido notablemente su eficacia. ${ }^{13}$ Por otro lado, el establecimiento de unos plazos temporales injustificadamente largos para el

la LIONDAU la accesibilidad universal se vincula de manera indisoluble a la no discriminación, a fin de satisfacer mediante ambas prácticas el objetivo fundamental de la igualdad de oportunidades de las personas con discapacidad. En el mismo sentido, en el apartado (v) del Preámbulo de la Convención (ONU, 2006) se destaca "la importancia de la accesibilidad al entorno físico, social, económico y cultural, a la salud y la educación y a la información y las comunicaciones, para que las personas con discapacidad puedan gozar plenamente de todos los derechos humanos y las libertades fundamentales". La accesibilidad es uno de los "Principios generales" que guían la Convención (art. 3), en la que se le dedica de manera íntegra su artículo 9. En sentido amplio, la accesibilidad se convierte así en un derecho instrumental y en una herramienta para la igualdad de oportunidades.

${ }^{13}$ La aprobación de tales regulaciones se demoró cuatro años, desde la aprobación de la LIONDAU: Ley 49/2007, de 26 de diciembre, por la que se establece el régimen de infracciones y sanciones en materia de igualdad de oportunidades, no discriminación y accesibilidad universal de las personas con discapacidad. 
cumplimiento de lo dispuesto en ella, ha producido que los derechos garantizados formalmente en la LIONDAU no se hiciesen efectivos (Díaz, 2008) ${ }^{14}$ Estas reminiscencias del tratamiento dado a la accesibilidad veinte años antes, en la LISMI, abundan en la consideración de una transición incompleta entre los discursos acerca de la discapacidad expresados en ambas leyes.

\section{A modo de conclusión}

El lento proceso de cambio de discurso, desde el discurso de la rehabilitación hacia el discurso de la autonomía personal, viene implicando, según hemos expuesto, diferentes elementos y dimensiones. Prácticas como la desmedicalización y la desinstitucionalización de las personas con discapacidad, consideradas como elementos inherentes al discurso de la autonomía personal en el espacio social, correlacionan con cambios en la representación de estas personas en el espacio legislativo, en el que comenzaron a ser consideradas plenamente como 'sujetos' de derechos en todos los entornos de la sociedad, en vez de como 'objeto' de prácticas normalizadoras en algunos de ellos. Aparte de los espacios en los que el cambio de discurso se ha verificado en mayor medida, la situación actual refleja principalmente la convivencia de ambos discursos, basada en el hecho de que los cambios de representación en el espacio legislativo no han llegado al espacio social, ni a los entornos educativo y laboral, ni a los espacios comunicativos e informacionales, culturales, artísticos, etc., ni, muy especialmente, tampoco al espacio actitudinal. Este es, en nuestra opinión, un aspecto clave sobre el que debería proyectarse la praxis de intervención. En todos estos espacios prevalece todavía el imaginario devaluante de representaciones negativas acerca de las personas con discapacidad, característico del discurso de la rehabilitación. Las personas con discapacidad siguen siendo consideradas en mayor medida como objetos de enunciado que como sujetos de enunciación (Fernández-Cid, 2010).

Podríamos decir que en el espacio legislativo se ha llevado a cabo en los últimos treinta años un cambio notable en la representación de las personas con discapaci-

\footnotetext{
${ }^{14}$ Así, por ejemplo, las disposiciones finales quinta a novena establecen un calendario de cumplimiento de las obligaciones de accesibilidad que llega a los diecisiete años en los ámbitos de la Administración Pública, bienes y servicios a disposición del público, acceso y utilización de tecnologías, medios de transporte y espacios públicos urbanizados y edificaciones. Atendiendo a estos plazos temporales, puede decirse claramente que la LIONDAU proyecta una sociedad accesible para las personas con discapacidad que vivan en España allá por el año 2020 (Courtis, 2004). Las modificaciones introducidas por la Ley 26/2011, de 1 de agosto, de adaptación normativa a la Convención Internacional sobre los Derechos de las Personas con Discapacidad, reducen el valor máximo de tales plazos de diecisiete a catorce años, lo que supone una muestra de la tibieza en el ánimo y en la redacción de esta ley (SOLCOM, 2011).
} 
dad: de la representación que las consideraba como objeto de atención especial y normalización, según el discurso de la rehabilitación, se ha pasado de manera progresiva a la representación vinculada al discurso de la autonomía personal, que las considera plenamente como sujetos de derechos (ONU, 1993; OMS, 2001; ONU, 2006). Este cambio de representación ha repercutido en numerosas prácticas llevadas a cabo en el espacio social, en el que se ha avanzado, por ejemplo, de la medicalización e institucionalización de las personas con discapacidad, hacia prácticas, todavía incompletas (SOLCOM, 2010, 2011), de desmedicalización y desinstitucionalización. No obstante, este cambio en el conjunto de prácticas no se ha visto acompañado de un cambio análogo en las representaciones de las personas con discapacidad en el mismo espacio social, donde todavía prevalecen las viejas representaciones devaluantes y negativas propias del discurso de la rehabilitación. Esta permanencia y fijación de las representaciones en el espacio social limita en gran medida el alcance del cambio producido en las prácticas y la posibilidad de que este cambio pueda extenderse a otros espacios, en la forma de cambios análogos en las viejas prácticas allí existentes.

Mencionemos, como ejemplos de espacios a la espera todavía de estos cambios y de la intervención necesaria, los siguientes: el espacio físico construido, en el que, además de unos plazos de introducción injustificadamente largos (BOE, 2003; Courtis, 2004), los requerimientos de accesibilidad se incumplen de manera sistemática, constituyendo la accesibilidad uno de los grandes fracasos de la política española en materia de discapacidad (IMSERSO, 2002; CERMI, 2009); el entorno educativo, en el que el logro de la educación inclusiva del alumnado con discapacidad continúa siendo actualmente una realidad lejana (Verdugo et al., 2009; CERMI, 2010; Echeita, 2011; SOLCOM, 2011); el entorno laboral, en el que, en el mejor de los casos, la presencia de las personas con discapacidad fuera de los Centros Especiales de Empleo es esporádica y en trabajos de baja cualificación, y en el peor ni siquiera se respetan, sobre todo en las empresas privadas, las cuotas de reserva introducidas en la legislación para combatir la desigualdad de oportunidades (Lidón, 2008); el acceso a la vida independiente, en el que la inclinación legislativa a favor de la atención a la dependencia desatiende la promoción de la autonomía personal (BOE, 2006) y dificulta el acceso a la asistencia personal, considerada como uno de sus recursos básicos (CERMI; 2009; Guzmán, Moscoso y Toboso, 2010; Díaz, 2010; SOLCOM, 2010); los espacios de la cultura, el ocio, la información y la comunicación, en los que, además del incumplimiento reiterado de la accesibilidad a entornos, productos y servicios, predominan los estereotipos e imágenes devaluantes de las personas con discapacidad (Casado, 2001; Ledesma, 2008; Fernández-Cid, 2010); el espacio de las relaciones personales, como espacio fundamental de realización y crecimiento de la persona que, más allá del ámbito familiar, se ve seriamente limitado por los obstáculos presentes en el resto de entonos (educativo, laboral, ocio, etc.); y, finalmente, de manera particular, el espacio actitudinal que, aunque escasamente señalado en la normativa (UE, 2000; BOE, 2003; ONU, 2006), constituye el depósito del imaginario social de representaciones negativas acerca de la discapacidad (Miller et al., 2004; Barriga, 2008; García de la Cruz, 2008), cuya 
permanencia se opone a los cambios y avances realizados en otros espacios, en relación a la creciente presencia y participación social normalizada de las personas con discapacidad.

\section{Bibliografía}

Abberley, Paul (1987). "The concept of opression and the development of a social theory of disability”. Disability, Handicap \& Society, 2, 5-19

Aguado, Antonio L. (1995). Historia de las deficiencias. Madrid. Escuela Libre Editorial. Colección Tesis y Praxis.

Arnau, Soledad y Toboso, Mario (2009). "La IN-dependencia: un nuevo derecho de ciudadanía. Una cuestión de Derechos Humanos”. En Casaban, Enric (2009). Actas del XVII Congrés Valencià de Filosofia. Valencia. Societat de Filosofia del País Valencià. 149-163.

http://digital.csic.es/bitstream/10261/23232/1/Arnau\%20y\%20Toboso_XVII\%20Co ngr\%C3\%AAs\%20Valenci\%C3\%A2\%202008.pdf

Barnes, Colin (1991). Disabled People in Britain and Discrimination. Londres. Hurst \& Co.

Barriga, José Julián (2008). “Imagen social y visibilidad de la discapacidad”. En Ledesma, José Antonio (ed.) (2008). La imagen social de las personas con discapacidad. Madrid. CINCA.

http://www.cermi.es/es-

ES/ColeccionesCermi/Cermi.es/Lists/Coleccion/Attachments/60/Laimagensocial delaspersonascondiscapacidad.pdf

Barton, Len (ed.) (1996). Disability and Society: Emerging Issues and Insights. Londres. Longman.

Berg, Marc (1998). “Order(s) and Disorder(s): Of Protocols and Medical Practices”. En Berg, Marc y Mol, Annemarie (eds.) Differences in Medicine: Unraveling Practices, Techniques, and Bodies. Durham, NC, and London: Duke University Press.

BOE (2006). Ley 39/2006, de 14 de diciembre, de Promoción de la Autonomía

Personal y Atención a las personas en situación de dependencia. Madrid. BOE.

http://www.boe.es/boe/dias/2006/12/15/pdfs/A44142-44156.pdf

BOE (2003). Ley 51/2003, de 2 de diciembre, de Igualdad de Oportunidades, No

Discriminación y Accesibilidad Universal de las personas con discapacidad. Madrid. BOE.

http://www.boe.es/boe/dias/2003/12/03/pdfs/A43187-43195.pdf

BOE (1982). Ley 13/1982, de 7 de abril, de Integración Social de los Minusválidos.

Madrid. BOE.

http://www.imserso.es/Presentacion/groups/imserso/documents/binario/ley13-

82.pdf

Brisenden, Simon (1986). "Independent Living and the Medical Model of Disability”. Disability, Handicap and Society, 1 (2), 173-178. 
Cabrera, Laura (2009) "Nanotechnology: Changing the Disability Paradigm". International Journal of Disability, Community \& Rehabilitation, vol. 8, n 2. http://www.ijdcr.ca/VOL08_02/articles/cabrera.shtml

Casado, Demetrio (2001). Comunicación social en discapacidad. Cuestiones éticas y de estilo. Madrid. Real Patronato sobre Discapacidad.

http://www.infodisclm.com/documentos/medios_comunicacion/com_social_disc.pd $\mathrm{f}$

CERMI (2010). Los jóvenes con discapacidad en España. Informe de situación 2010. Madrid. Cinca.

http://www.intersocial.es/images/stories/pdf/jovenes_con_discapacidad.pdf

CERMI (2009). Derechos humanos y discapacidad. Informe España 2008. Madrid. Cinca

http://sid.usal.es/idocs/F8/FDO22150/DerechosHumanos.pdf

Comisión Europea (2000). "Hacia una Europa sin barreras para las personas con discapacidad”. Bruselas. COM (2000) 284 final. http://eur-

lex.europa.eu/LexUriServ/LexUriServ.do?uri=COM:2000:0284:FIN:ES:PDF

Courtis, Christian (2004). "Discapacidad e inclusión social: retos teóricos y desafíos prácticos. Algunos comentarios a partir de la Ley 51/2003”. Jueces para la democracia, $\mathrm{n}^{\circ} 51$.

Díaz, Eduardo (2010). “¿Políticas sociales de dependencia o de promoción de la autonomía?” Zerbitzuan, nº 48, 33-41.

http://www.zerbitzuan.net/documentos/zerbitzuan/Politicas\%20sociales\%20de\%20 dependencia.pdf

(2009). "Reflexiones epistemológicas para una sociología de la discapacidad". Intersticios, 3(2), 85-99.

http://www.intersticios.es/article/view/4557/3177

(2008). Ciudadanía y discapacidad: Un análisis sociológico de la normativa jurídica y las principales políticas públicas en España. Tesina doctoral. Departamento de Sociología II, Cambio Social. Facultad de Ciencias Políticas y Sociología, Universidad Complutense de Madrid.

Echeita, Gerardo (2011). "El proceso de inclusión educativa en España. ¡Quien bien te quiere te hará llorar!” CEE Participación Educativa, 18, noviembre 2011, 117-128.

http://www.educacion.gob.es/revista-cee/pdf/n18-echeita-sarrionandia.pdf

Echeverría, Javier (2003): "Science, technology, and values: towards an axiological analysis of techno-scientific activity”. Technology in Society, 25, 205-215.

(2002a): Ciencia y valores, Barcelona, Destino.

(2002b): “Axiología y Ontología: los valores de la ciencia como funciones no saturadas”. Argumentos de Razón Técnica, nº 5, 21-37. http://institucional.us.es/revistas/argumentos/5/art_1.pdf (1995): “El pluralismo axiológico de la ciencia”. Isegoría, no 12, 44-79. http://isegoria.revistas.csic.es/index.php/isegoria/article/view/240/240 
Egea, Carlos y Sarabia, Alicia (2001). "Clasificación de la OMS sobre discapacidad”. Boletín del Real Patronato sobre Discapacidad, N. 50, 15-30.

http://sid.usal.es/idocs/F8/ART6594/clasificacion_oms.pdf

European Commission (2001). "Discrimination by design" (Background Paper). In

Conference, Brussels, 3rd December.

http://www.accessibletourism.org/resources/dfa_ia_en.pdf.

Fernández-Cid, Matilde (2010). "Medios de comunicación, conformación de ima-

gen y construcción de sentido en relación a la discapacidad". Política y sociedad, 47 (1), 105-113.

http://revistas.ucm.es/index.php/POSO/article/view/POSO1010130105A/21696

Finkelstein, Vic (1980). Attitudes and Disabled People: Issues for Discussion.

Nueva York. World Rehabilitation Fund.

García de la Cruz, Juan José (2008). "La inevitable estigmatización de las personas con discapacidad”. En Ledesma, José Antonio (ed.) (2008). La imagen social de las personas con discapacidad. Madrid. CINCA. http://www.cermi.es/es-

ES/ColeccionesCermi/Cermi.es/Lists/Coleccion/Attachments/60/Laimagensocial delaspersonascondiscapacidad.pdf

García-Alonso, J. Vidal (coord.) (2003). El movimiento de vida independiente.

Experiencias Internacionales. Madrid. Fundación Luís Vives.

http://www.independentliving.org/docs6/alonso2003.pdf

Garfinkel, Harold (2006 [1967]). Estudios en etnometodología. Barcelona. Anthropos.

Guzmán, Francisco; Moscoso, Melania y Toboso, Mario (2010). "Por qué la Ley de

Dependencia no constituye un instrumento para la promoción de la autonomía personal". Zerbitzuan, $\mathrm{n}^{\circ}$. 48, 43-56.

http://www.zerbitzuan.net/documentos/zerbitzuan/Ley\%20de\%20dependencia\%20

no\%20constituye\%20un\%20instrumento.pdf

Guzmán, Francisco; Toboso, Mario y Romañach, Javier (2010). "Fundamentos éticos para la promoción de la autonomía: hacia una ética de la interdependencia”. Alternativas: cuadernos de trabajo social, No. 17, 45-62.

http://rua.ua.es/dspace/bitstream/10045/14296/1/Alternativas_17_03.pdf

Hunt, Paul (1966). “A Critical Condition”. En Hunt, P. (ed.) (1966). Stigma: The Experience of Disability. Londres. Geoffrey Chapman.

IMSERSO (2004). I Plan Nacional de Accesibilidad, 2004-2012. Madrid. IMSERSO.

http://www.imsersomayores.csic.es/documentos/documentos/mtas-

planaccesibilidad-01.pdf

Jiménez, Antonio y Huete, Agustín (2010). "Políticas públicas sobre discapacidad en España. Hacia una perspectiva basada en los derechos”. Política y Sociedad, 47 (1), 137-152.

http://revistas.ucm.es/index.php/POSO/article/view/POSO1010130137A/21706 
Jordan, Kathleen y Lynch, Michael (1998). "The Dissemination, Standardization and Routinization of a Molecular Biological Technique”. Social Studies of Science, Vol. 28, No. 5/6, 773-800.

King, M. D. (1971). "Reason, Tradition, and the Progressiveness of Science". History and Theory, Vol. 10, No. 1, 3-32.

Kuhn, Thomas S. (1979 [1962]). La estructura de las revoluciones científicas. México. Fondo de Cultura Económica.

Ledesma, José Antonio (ed.) (2008). La imagen social de las personas con discapacidad. Madrid. CINCA.

http://www.cermi.es/es-

ES/ColeccionesCermi/Cermi.es/Lists/Coleccion/Attachments/60/Laimagensocial delaspersonascondiscapacidad.pdf

Lidón, Leonor. (2008). Derechos humanos y discapacidad en España. Informe de situación. Fundación ONCE 2007. Madrid. Cinca.

http://info.telefonica.es/ext/accesible/html/home//pdf/006_ColeccTA_DERECHOS UMANOS-DISCAPA.pdf

Livingston, Eric (1999). "Cultures of Proving”. Social Studies of Science, Vol. 29, No. 6, 867-888.

Lupton, Deborah (1995). The Imperative of Health. Public health and the regulated body. Thousand Oaks, California: Sage.

Lynch, Michael (1988). "Sacrifice and the Transformation of the Animal Body into a Scientific Object: Laboratory Culture and Ritual Practice in the Neurosciences”. Social Studies of Science, Vol. 18, No. 2, 265-289.

Lynch, Michael y Woolgar, Steve (1988). "Introduction: Sociological orientations to representational practice in science”. Human Studies, 11, 99-116.

Martínez-Pérez, José (2009). "Consolidando el modelo médico de discapacidad: sobre la poliomielitis y la constitución de la traumatología y ortopedia como especialidad en España (1930-1950)”. Asclepio, Vol. 61, No. 1, 117-142.

http://asclepio.revistas.csic.es/index.php/asclepio/article/view/274/270

Miller, Paul; Parker, Sophia y Gillison, Sarah (2004). Disablism. How to tackle the last prejudice. Londres. Demos.

Mol, Annemarie (2002). The Body Multiple: Ontology in Medical Practice. Durham. Duke University Press.

Morris, Jenny (1991). Pride against Prejudice: Transforming Attitudes to Disability. Londres. The Women's Press.

Oliver, Mike (1990). The politics of disablement. Londres. Macmillan.

(1996). Understanding Disability: From Theory to Practice. Londres. Macmillan.

OMS (2001). Clasificación Internacional del Funcionamiento, de la Discapacidad y de la Salud. Madrid. IMSERSO.

ONU (2006) Convención sobre los Derechos de las Personas con Discapacidad y Protocolo Facultativo. Nueva York. ONU.

http://www.un.org/disabilities/documents/convention/convoptprot-s.pdf

ONU (1993): Normas Uniformes sobre la igualdad de oportunidades para las personas con discapacidad. Nueva York. ONU. 
http://www.un.org/spanish/disabilities/standardrules.pdf

ONU (1982): Programa de Acción Mundial para las Personas con Discapacidad.

http://www.un.org/spanish/disabilities/default.asp?navid=7\&pid=500

Palacios, Agustina (2008). El modelo social de la discapacidad: orígenes, caracte-

rización y plasmación en la Convención Internacional sobre los Derechos de las

Personas con Discapacidad. Madrid. Ediciones Cinca.

http://www.convenciondiscapacidad.es/Publicaciones/El\%20modelo\%20social\%20 de\%20discapacidad.pdf

Palacios, Agustina y Francisco Bariffi (2007). La discapacidad como una cuestión de derechos humanos. Una aproximación a la Convención Internacional sobre los Derechos de las Personas con Discapacidad. Madrid: Ediciones Cinca.

http://www.convenciondiscapacidad.es/Publicaciones

/Libro\%20Agustina\%20Discapacidad.pdf

Parra-Dussan, Carlos (2010). "Convención sobre los Derechos de las Personas con

Discapacidad: antecedentes y sus nuevos enfoques”. International Law, Revista

Colombiana de Derecho Internacional, 347-380.

http://redalyc.uaemex.mx/src/inicio/ArtPdfRed.jsp?iCve=82420041011

Rodríguez, Susana y Ferreira, Miguel A. V. (2010). "Desde la dis-capacidad hacia

la diversidad funcional”. Revista Internacional de Sociología, Vol. 68. № 2, 289-309.

http://revintsociologia.revistas.csic.es/index.php/revintsociologia/article/view/333/3

39

Shakespeare, Tom (1993). "Disabled people's self-organization: a new social movement?” Disability, Handicap \& Society, vol. 8, n. ${ }^{\circ} 3,249-264$.

SOLCOM (2011). Informe SOLCOM 2011. Derechos Humanos en España. Madrid. Asociación SOLCOM.

http://www.asociacionsolcom.org/files/documentos/informe_solcom_2011.pdf

(2010). Informe SOLCOM 2010. Derechos Humanos en España. Madrid. Asociación SOLCOM.

http://www.asociacionsolcom.org/files/documentos/Informe_SOLCOM_2010.pdf

Stiker, Henri-Jaques. (1999). A History of Disability. The University of Michigan Press.

Swain, John; French, Sally; Barnes, Colin y Thomas, Carol (2004). Disabling barriers-Enabling Enviroments. London. Sage.

Toboso, Mario y Guzmán, Francisco (2010). "Cuerpos, capacidades, exigencias

funcionales... y otros lechos de Procusto”. Política y Sociedad, 47 (1), 67-83.

http://revistas.ucm.es/index.php/POSO/article/view/POSO1010130067A/21682

(2009). "Diversidad funcional: hacia la deconstrucción del cuerpo funcionalmente

normativo". En Actas del I Congreso Internacional de Cultura y Género: La

Cultura en el Cuerpo. Elche. Universidad Miguel Hernández.

http://digital.csic.es/bitstream/10261/23424/1/Toboso\%20y\%20Guzm\%C3\%A1n_S

IEG\%20I\%20Congreso\%202009.pdf

Topliss, Eda (1982). Social Responses to Handicap. Harlow. Longman. 
Verdugo, Miguel Ángel; Rodríguez, Alba; Sarto, Pilar; Calvo, Isabel y Santamaría, Mónica (2009). "Situación de la inclusión educativa en España”. En VV. AA. (2009). La educación que queremos. Situación actual de la inclusión educativa en España. Madrid. FEAPS.

http://www.feaps.org/archivo/publicaciones-feaps/libros/coleccion-feaps/297-laeducacion-que-queremos-situacion-actual-de-la-inclusion-educativa-enespana.html

Woolgar, Steve (1986): On the Alleged Distinction between Discourse and Praxis. Social Studies of Science, vol. 16, $\mathrm{n}^{\circ}$ 2, 309-317 